\title{
Evidence-based scientific exercise guidelines for adults with spinal cord injury: an update and a new guideline
}

\author{
Kathleen A. Martin Ginis $\mathbb{D}^{1,2} \cdot$ Jan W. van der Scheer ${ }^{3}$ Amy E. Latimer-Cheung ${ }^{4}$ - Andy Barrow ${ }^{5}$. Chris Bourne ${ }^{6}$. \\ Peter Carruthers ${ }^{7} \cdot$ Marco Bernardi $^{8} \cdot$ David S. Ditor $^{9} \cdot$ Sonja Gaudet $^{10} \cdot$ Sonja de Groot ${ }^{11} \cdot$ Keith C. Hayes $^{12}$. \\ Audrey L. Hicks ${ }^{13}$. Christof A. Leicht ${ }^{3} \cdot$ Jan Lexell $^{14} \cdot$ Steven Macaluso $^{15}$ - Patricia J. Manns ${ }^{16}$. \\ Christopher B. McBride ${ }^{10} \cdot$ Vanessa K. Noonan $^{17} \cdot$ Pierre Pomerleau $^{18} \cdot$ James H. Rimmer $^{19} \cdot$ Robert B. Shaw $^{1}$. \\ Brett Smith $^{20}$ - Karen M. Smith ${ }^{3}$ - John D. Steeves ${ }^{2} \cdot$ Dot Tussler $^{21} \cdot$ Christopher R. West $^{1} \cdot$ Dalton L. Wolfe $^{22}$. \\ Victoria L. Goosey-Tolfrey ${ }^{2}$
}

Received: 6 May 2017 / Revised: 14 September 2017 / Accepted: 20 September 2017 / Published online: 25 October 2017

(c) The Author(s) 2018. This article is published with open access

\begin{abstract}
Objectives To describe the process and outcomes of using a new evidence base to develop scientific guidelines that specify the type and minimum dose of exercise necessary to improve fitness and cardiometabolic health in adults with spinal cord injury (SCI).

Setting International.

Methods Using Appraisal of Guidelines, Research and Evaluation (AGREE) II reporting criteria, steps included (a) determining the guidelines' scope; (b) conducting a systematic review of relevant literature; (c) holding three consensus panel meetings (European, Canadian and International) to formulate the guidelines; (d) obtaining stakeholder feedback; and (e) process evaluation by an AGREE II consultant. Stakeholders were actively involved in steps (c) and (d).

Results For cardiorespiratory fitness and muscle strength benefits, adults with a SCI should engage in at least 20 min of moderate to vigorous intensity aerobic exercise 2 times per week AND 3 sets of strength exercises for each major functioning muscle group, at a moderate to vigorous intensity, 2 times per week (strong recommendation). For cardiometabolic health benefits, adults with a SCI are suggested to engage in at least $30 \mathrm{~min}$ of moderate to vigorous intensity aerobic exercise 3 times per week (conditional recommendation).

Conclusions Through a systematic, rigorous, and participatory process involving international scientists and stakeholders, a new exercise guideline was formulated for cardiometabolic health benefits. A previously published SCI guideline was endorsed for achieving fitness benefits. These guidelines represent an important step toward international harmonization of exercise guidelines for adults with SCI, and a foundation for developing exercise policies and programs for people with SCI around the world.
\end{abstract}

\section{Introduction}

Physical activity (PA) guidelines are systematically developed, evidence-based statements that provide age- and ability-specific information on the course of action required

Electronic supplementary material The online version of this article (https://doi.org/10.1038/s41393-017-0017-3) contains supplementary material, which is available to authorized users.

Kathleen A. Martin Ginis

kathleen_martin.ginis@ubc.ca

Extended author information available on the last page of the article to maintain or enhance performance, fitness, or health [1]. Over the past decade, national and international agencies have developed and disseminated PA guidelines for the general population [2-5], derived from systematic reviews of dose-response evidence regarding the amount of PA required to reduce morbidity or mortality rates (e.g., ref. $[3,6]$ ). The World Health Organization (WHO), for instance, recommends at least $150 \mathrm{~min} /$ week of moderateintensity aerobic activity (or $75 \mathrm{~min} /$ week of vigorousintensity aerobic activity), plus muscle-strengthening activities twice per week [3].

However, the WHO and other national public health PA guidelines were not specifically tailored to the SCI 
population. Indeed, the WHO guideline is presented with the caveat: "These recommendations can be applied to adults with disabilities. However they may need to be adjusted for each individual based on their exercise capacity and specific health risks or limitations" [3]. Furthermore, rigorous clinical practice guidelines should be formulated by taking into consideration the benefits, risks, values, and preferences of the people who will use the guideline [7, 8]. Not only were studies of people with SCI essentially excluded from the systematic reviews underpinning public health PA guidelines (e.g., ref. [6]), but the potential risks of SCI-specific adverse events (e.g., upper-body over-use injuries [9], skin breakdown [10], autonomic dysreflexia [11], over-heating [12]) were not considered in relation to performing the $150 \mathrm{~min} /$ week guideline. Likewise, no consideration was given to the feasibility of the guideline in the SCI population. Because people with SCI face tremendous physical, psychosocial and environmental barriers to PA $[13,14]$, they are less active and more physically deconditioned than both the general population and individuals with many other types of disabilities [15, 16]. These issues, coupled with 'overwhelming evidence' that people living with disability can achieve health benefits from activity levels well below the $150 \mathrm{~min} /$ week threshold [17], highlight the need to re-consider the appropriateness of promoting the $150 \mathrm{~min} /$ week guideline in the SCI population [18].

In 2011, a Canadian team developed evidence-based, SCI-specific PA guidelines [19], using the same transparent, rigorous and systematic process used to formulate WHO and national PA guidelines [2-5]. This process followed the Appraisal of Guidelines for Research and Evaluation (AGREE) II criteria [8], considered the gold-standard for developing and reporting clinical practice guidelines [7, 20]. The team produced the following guideline: "For important fitness benefits, adults with a spinal cord injury should engage in at least $20 \mathrm{~min}$ of moderate to vigorous intensity aerobic activity two times per week, and strength training exercises two times per week" [19]. This guideline has been translated into over a dozen languages, distributed and adopted internationally, and proven efficacious for improving fitness in adults with SCI [21]. A limitation, however, is that it does not specifically address cardiometabolic health, which encompasses measures of body composition (e.g., fat mass, lean body mass)[22, 23] and risk factors for cardiovascular disease (e.g., blood lipids and cardiac vascular structure/function) [24-26]. A lack of highquality research evidence regarding the effects of PA on health outcomes precluded the formulation of a cardiometabolic health guideline in 2011 [19]. Because cardiometabolic diseases are among the leading causes of death in adults with SCI [27], guidelines that address cardiometabolic health would be extremely valuable.
A recent systematic review provided a synthesis and appraisal of research testing the effects of exercise interventions on fitness and health outcomes in adults with SCI [28]. The authors reported moderate-to-high confidence in the evidence showing exercise can improve fitness and cardiometabolic health outcomes in adults with chronic SCI. Furthermore, they reported low-to-moderate confidence in the evidence supporting specific exercise prescriptions (i.e., the exercise type and the 'dose' of exercise given to participants, consisting of exercise frequency, intensity and duration) [29] leading to significant improvements in these outcomes. The evidence was insufficient to derive dose-response relationships between exercise and fitness and cardiometabolic health outcomes 28]. However, it seems that since the 2011 guideline development process, sufficient evidence has accumulated to underpin the formulation of exercise guidelines that specify the type and minimum dose of exercise necessary to improve cardiometabolic health in adults with chronic SCI. Clinical practice guidelines should be kept up-to-date with current evidence [8]. Accordingly, the purpose of this paper is to describe the process and outcomes of using the new evidence base [28], along with AGREE II reporting criteria [20], to develop scientific guidelines that specify the type and minimum dose of exercise necessary to improve fitness and cardiometabolic health in adults with SCI.

\section{Methods}

\section{Project overview}

The project leadership team consisted of four researchers with expertize in PA and SCI (KAMG, JWvdS, AEL-C, VG-T) and developing PA guidelines (KAMG and AEL-C). The team established the project objective as to develop scientific guidelines that specify the type and minimum dose of exercise necessary to improve fitness and cardiometabolic health in adults with SCI. The focus on 'exercise' (i.e., planned, structured, and repetitive PA that is performed to maintain or improve fitness) [30] rather than 'PA' (i.e., any bodily movement produced by skeletal muscles requiring energy expenditure) [30] reflected the contents of the new evidence base/systematic review [28]. Although the new review was designed to capture all forms of PA interventions (e.g., sport, lifestyle activity, exercise), $99 \%$ of the studies involved structured exercise interventions [28].

The process, and its reporting in this manuscript, were guided by the AGREE II Instrument [8] and AGREE reporting checklist [20] which specify 23 items, across six domains (scope and purpose; stakeholder involvement; rigor of development; clarity of presentation; applicability; editorial independence), to report when formulating a 
clinical practice guideline. Steps involved: (a) determining the scope of the guidelines; (b) conducting a systematic review of relevant literature; (c) holding three consensus panel meetings (European, Canadian, International) to formulate the guidelines; (d) obtaining stakeholder feedback; and (e) a process audit by an AGREE II consultant. Stakeholders (e.g., people living with SCI, health care providers, service provider organizations) were actively involved in steps (c) and (d).

\section{Systematic review}

The guideline's evidence base was provided by a systematic review that synthesized and appraised research testing the effects of exercise interventions on fitness (cardiorespiratory fitness, power output and/or muscle strength), cardiometabolic health (body composition and/or cardiovascular risk factors), and bone health outcomes among adults with SCI [28]. Two leadership team members (JWvdS, KAMG) led the review and a third (VG-T) was a co-author. The review was undertaken in collaboration with the Spinal Cord Injury Research Evidence (SCIRE) project (https://scireproject. com).

The review is fully described by Van der Scheer et al [28]. In brief, included studies: employed exercise interventions for a period $\geq 2$ weeks; involved adults with acute or chronic SCI; and measured fitness, cardiometabolic health and/or bone health outcomes. No exclusion criteria were set for type of exercise intervention, participant age, cause or characteristics of SCI, baseline PA level, or comorbid conditions. All study designs except case studies were included. Each study was rated for its level of evidence (Levels 1-4) based on strength of the study design and cut-off scores on quality checklists (i.e., the Physiotherapy Evidence Database Scale and a modified Downs and Black scale) $[28,31]$.

Evidence was considered separately for acute ( $\leq$ 12 months post-injury) and chronic SCI. First, evidence was synthesized and appraised (using Grading of Recommendations, Assessment, Development, and Evaluation [GRADE]) [7, 32] regarding the overall effects of exercise on each reviewed outcome (Table 1). Second, evidence was synthesized and appraised for the effects of specific exercise prescriptions on each outcome (Table 2), but only for those types of exercise used in at least two Level 1 or 2 studies. Using this information, the review authors drafted a set of guideline recommendations that captured the type of exercise and range of specific exercise frequencies, intensities and durations yielding significant improvements in each outcome. Because two high-quality studies are considered the minimum for developing clinical practice guidelines, guideline recommendations could not be drafted for exercise types (e.g., functional electrical stimulation [FES])
Table 1 GRADE confidence ratings for the evidence presented in the systematic review [28] regarding the effects of exercise on each of the reviewed outcomes for adults with acute SCI or chronic SCI

\begin{tabular}{llll}
\hline Outcome & $\begin{array}{l}\text { Acute } \\
\text { SCI (any } \\
\text { adult) }\end{array}$ & $\begin{array}{l}\text { Chronic } \\
\text { SCI (any } \\
\text { adult) }\end{array}$ & $\begin{array}{l}\text { Chronic SCI } \\
\text { (young and middle- } \\
\text { aged adults) }\end{array}$ \\
\hline $\begin{array}{l}\text { Fitness } \\
\text { Cardiorespiratory fitness }\end{array}$ & $\begin{array}{l}\text { Very low } \\
\text { Power output }\end{array}$ & Mederate & High \\
Muscle strength & Very low & Moderate & High \\
Cardiometabolic health & & & \\
Body composition & Very low & Moderate & High \\
Cardiovascular risk & Very low & Moderate & High \\
Bone health & Very low & Very low & Very low \\
\hline
\end{tabular}

$G R A D E$ grading of recommendations, assessment, development, and evaluation [7,32], SCI spinal cord injury

with $<2$ Level 1 or 2 studies available [33]. Finally, reported adverse event data were summarized [27].

\section{Consensus panel meetings}

To maximize international stakeholders' involvement and bolster confidence in the rigor and scrutiny of the guideline development process, three separate, 1-day consensus panel meetings were held to review the evidence and formulate the guidelines. The first meeting was held on June 21, 2016 at Loughborough University, UK. European scientists with expertize in SCI and PA were invited to participate, along with clinicians and two SCI consumers (i.e., adults living with SCI). The meeting was observed by a post-doctoral fellow and a knowledge translation specialist who took notes. The second meeting was on October 24, 2016, in Toronto, Canada. Canadian scientists with expertize in SCI and PA were invited to participate, along with clinicians, representatives of community organizations, and one SCI consumer (a second consumer withdrew the night before the meeting). A research coordinator observed the meeting and took notes. The third meeting occurred on November 23, 2016 in Kelowna, Canada. The purpose of this International meeting was to create consensus across the European and Canadian meetings. A scientific representative from both previous meetings attended, along with two scientists and a clinician-scientist who developed SCI PA guidelines in their home countries (Australia, Sweden, United States), two SCI consumers, and representatives from national and international SCI organizations. The meeting was observed by a doctoral student/clinician and a graduate student who took notes. A full list of panel members is presented in online Supplement 1.

KAMG chaired the European and International meetings and AEL-C chaired the Canadian meeting. Both chairs are 
Table 2 GRADE confidence ratings [10, 24] for the evidence used to formulate the guideline recommendations [28] (i.e., the range of exercise durations, frequencies and intensities associated with significant improvements in an outcome)

\begin{tabular}{|c|c|c|c|c|c|}
\hline \multirow[t]{2}{*}{ Outcome [3] } & \multicolumn{2}{|c|}{$\begin{array}{l}\text { Combined upper-body aerobic plus strength } \\
\text { exercise }^{\mathrm{a}}\end{array}$} & \multicolumn{3}{|c|}{ Upper-body aerobic exercise only ${ }^{\mathrm{b}}$} \\
\hline & $\begin{array}{l}\text { Adults of any age } \\
\text { with chronic SCI } \\
\text { and AIS A-D }\end{array}$ & $\begin{array}{l}\text { Young and middle-aged } \\
\text { adults with chronic SCI } \\
\text { and AIS A-D }\end{array}$ & $\begin{array}{l}\text { Adults of any age } \\
\text { with chronic SCI } \\
\text { and AIS A-D }\end{array}$ & $\begin{array}{l}\text { Young and middle-aged } \\
\text { adults with chronic SCI } \\
\text { and AIS A-B }\end{array}$ & $\begin{array}{l}\text { Young and middle-aged } \\
\text { adults with chronic SCI } \\
\text { and AIS C-D }\end{array}$ \\
\hline \multicolumn{6}{|l|}{ Fitness } \\
\hline Cardiorespiratory fitness & Low & Moderate & Low & Moderate & Low \\
\hline Power output & Low & Moderate & $\begin{array}{l}\text { Insufficient } \\
\text { evidence }\end{array}$ & Insufficient evidence & Insufficient evidence \\
\hline Muscle strength & Low & Moderate & Low & Moderate & Moderate \\
\hline \multicolumn{6}{|l|}{ Cardiometabolic health } \\
\hline Body composition & $\begin{array}{l}\text { Insufficient } \\
\text { evidence }\end{array}$ & Insufficient evidence & Low & Moderate & Low \\
\hline Cardiovascular risk & $\begin{array}{l}\text { Insufficient } \\
\text { evidence }\end{array}$ & Insufficient evidence & Low & Moderate & Low \\
\hline
\end{tabular}

AIS American spinal injury association impairment scale, GRADE grading of recommendations, assessment, development, and evaluation [7,32], $S C I$ spinal cord injury

${ }^{a}$ Guideline recommendation from the systematic review: $2-3$ sessions per week of moderate to vigorous intensity upper-body aerobic exercise for 20-30 min (cardiorespiratory fitness) or 20-40 min (power output and muscle strength) combined with upper-body strength exercise (3 sets of 10 repetitions, at 50-80\% 1RM for all large muscle groups). See Table 3 and table e-10 of the systematic review for more details [28]

${ }^{b}$ Guideline recommendation from the systematic review: 3-5 sessions per week of moderate to vigorous intensity upper-body aerobic exercise for 20-44 min (cardiorespiratory fitness) or 30-44 min (muscle strength, body composition and cardiovascular risk). See Table 4 and table e-11 of the systematic review for more details [28]

SCI and PA scientists, with extensive expertize in AGREE II and PA guideline development processes, and have chaired and attended numerous PA guideline panels. Prior to the meeting, the European panel received drafts of the systematic review evidence tables only, as a complete draft of the systematic review paper was not yet available. The Canadian and International panels received a complete draft of the systematic review paper [28]. To minimize potential bias, the Canadian panel was not informed of the European panel meeting results. The International panel received a 12page document summarizing the processes and outcomes from the European and Canadian meetings. This information facilitated an iterative process whereby the International panel could build on the discussions and consensus of the European and Canadian panels, leading to a final consensus decision.

Meeting agendas (Supplement 2) were structured to ensure discussion of issues required to meet AGREE II reporting criteria [20]. To start each meeting, panelists were asked to declare any conflicts of interest. Next, JWvdS presented an overview of the systematic review methods and results, and answered questions regarding these elements.

To assist in formulating the guidelines, as a starting point, the European and Canadian panelists were presented with the guideline recommendations from the systematic review [28]. The recommendations were the types and the

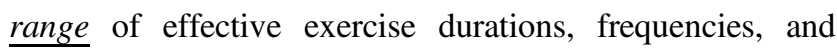
intensities (Table 2). The panel was tasked with formulating guidelines that reflected the minimum dose of exercise required to achieve benefits. At the International meeting, the starting point was the guidelines that emerged from the European and Canadian panel meetings. Evidence for acute and chronic SCI was considered separately and discussed until panels achieved consensus on a set of guidelines. The panel then graded the strength of these guidelines using GRADE [34,35], taking into account potential health benefits and risks of following the guidelines.

To be consistent with how PA guidelines are presented to the general population, the Canadian and International panels developed a scientific preamble (Fig. 1). The European panel did not have time to complete this task. The scientific preamble clearly describes the scope and purpose of the guidelines (i.e., the objective, outcomes covered, and the population to whom the guidelines apply). The Canadian panel used the preamble from the 2011 SCI PA guidelines [19] as a starting point, and the International panel started with the preamble developed by the Canadian panel. Consistent with AGREE II [8], the Canadian and International panels also discussed barriers and facilitators to implementing the guidelines. These discussions did not influence the content of the guidelines, but were intended to highlight challenges and opportunities for their dissemination. 


\section{Stakeholder involvement}

Stakeholders played a critical role in developing the guidelines. Fifteen stakeholders representing SCI consumers and other stakeholder groups (e.g., SCI community service providers, health care providers, exercise professionals) participated in the expert panels (Supplement 1). In addition, KAMG led a workshop at the 2016 ISCoS meeting to present an overview of the guideline project, along with the evidence and guideline recommendations from the systematic review [28]. Workshop participants were invited to provide feedback on the guideline development process through a survey ( $N=30$ responded; Table 3 ). After the International panel meeting, a survey about the guidelines was circulated to gain additional stakeholder feedback from SCI consumers $(N=45)$ and SCI clinicians $(N=13)$ who previously agreed to be contacted (Table 4). All survey protocols were reviewed and approved by the Okanagan Research Ethics Board at the University of British Columbia (Canada).

\section{AGREE II evaluation}

An AGREE II expert formally audited and evaluated the guideline development process. She was provided with the systematic review [28], and this manuscript, and completed the audit using the AGREE II Online Guideline Appraisal Tool (http://www.agreetrust.org).

\section{Results}

\section{Systematic review}

The review is fully described by Van der Scheer et al [28]. In brief, 211 studies met the inclusion criteria. For the body of evidence for acute SCI (22 studies), GRADE confidence ratings were very low for the effects of exercise on each outcome (Table 1). The lack of sufficient high-quality studies prohibited drafting a guideline recommendation for the use of exercise to improve any of the outcomes in adults with acute SCI. For the body of evidence for chronic SCI (189 studies), GRADE confidence ratings were moderate for evidence showing exercise can improve each reviewed outcome except bone health (Table 1). The only limitation of the evidence was indirectness: adults aged $>65 \mathrm{y}$ were virtually absent from the reviewed studies. Thus, for young and middle-aged adults it was concluded that there is high confidence in the evidence showing exercise can improve all of the reviewed outcomes except bone health.

Regarding specific exercise prescriptions, there was sufficient high-quality evidence to draft guideline recommendations for two types of exercises: (1) combined upperbody aerobic plus strength exercise; and (2) upper-body aerobic exercise only (see Table 2). The first recommendation (2-3 sessions per week of moderate to vigorous intensity upper-body aerobic exercise for 20-30 min combined with upper-body strength exercise [3 sets of 10 repetitions, at 50-80\% 1RM for all large muscle groups]) applied to all three fitness outcomes and was supported by evidence that included young and middle-aged adults with chronic SCI with A, B, C and D injuries on the American spinal injury association impairment scale (AIS). Low GRADE confidence ratings were established given imprecision and indirectness, caused by the absence of adults aged $>65 \mathrm{y}$. However, there was moderate confidence in the evidence showing this exercise prescription can yield significant improvements in fitness of young and middle-aged adults with chronic SCI.

The second, aerobic-only guideline recommendation (3-5 sessions per week of moderate to vigorous intensity upper-body aerobic exercise for $20-44 \mathrm{~min}$ [to improve cardiorespiratory fitness] or 30-44 min [to improve muscle strength, body composition and cardiovascular risk]) was applicable to two of the three fitness outcomes and both cardiometabolic health outcomes. It was supported by evidence including young and middle-aged adults with chronic SCI and AIS A and B. Low GRADE confidence ratings were established given imprecision and indirectness, caused by the absence of adults aged $>65 \mathrm{y}$ and/or adults with AIS $\mathrm{C}$ or D. However, there was moderate confidence in the evidence showing this exercise prescription can yield significant improvements in fitness of young and middle-aged adults with chronic SCI and AIS A-B. A summary of the GRADE evaluation of the evidence for each guideline recommendation is presented in Table 2.

The limited adverse event data for upper-body aerobic and/or strength exercise (derived from 5 studies involving 99 participants) suggested adverse events were rare, except for occasional incidence of musculoskeletal pain.

\section{Meetings}

This section documents the final consensus decisions achieved at the International panel meeting.

\section{Scope and purpose of the guidelines}

Overall objective of the guidelines. To specify the type and minimum dose of exercise necessary to improve fitness and cardiometabolic health in adults with SCI.

Questions covered by the guidelines. Based on the best available scientific evidence from studies involving adults with SCI, what is the type of exercise, and the minimum frequency, intensity, and durations (FITT principle) of exercise, needed to elicit fitness and cardiometabolic health 
Fig. 1 The guideline preamble

These exercise guidelines provide minimum thresholds for achieving the following benefits: (1) improved cardiorespiratory fitness and muscle strength, and (2) improved cardiometabolic health.

The guidelines should be achieved above and beyond the incidental physical activity one might accumulate in the course of daily living. Adults are encouraged to participate routinely in exercise modalities and contexts that are sustainable, enjoyable, safe, and reasonably achievable.

These guidelines are appropriate for adults (ages 18-64) with chronic spinal cord injury (at least 1 year post-onset, neurological level of injury $\mathrm{C} 3$ and below), from traumatic or non-traumatic causes, including tetraplegia and paraplegia, irrespective of sex, race, ethnicity or socio-economic status.

Before starting an exercise program, adults with SCI should consult with a health professional who is knowledgeable in the types and amounts of exercise appropriate for people with SCI. Individuals with a cervical or high thoracic injury should be aware of the signs and symptoms of autonomic dysreflexia during exercise.

For adults who are not already exercising, it is appropriate to start with smaller amounts of exercise and gradually increase duration, frequency, and intensity, as a progression toward meeting the guidelines. Doing exercise below the recommended levels may or may not bring small changes in fitness or cardiometabolic health.

The risks associated with these guidelines are minimal when managed in consultation with a health care professional who is knowledgeable in spinal cord injury.

The guidelines may be appropriate for individuals with a SCI $<12$ months post-onset, aged 65 years or older, or living with comorbid conditions. There is currently insufficient scientific evidence to draw firm conclusions about the risks and benefits of the guidelines for these individuals. These individuals should consult a health care provider prior to beginning an exercise program.

Exceeding these exercise guidelines would be expected to yield additional cardiorespiratory fitness and muscle strength and cardiometabolic health benefits. However, there are insufficient data to comment on the risks associated with a person with SCI exceeding these guidelines. benefits for adults with SCI? The guidelines are positioned as scientific guidelines meaning that they are wholly evidence-based and have not undergone knowledge translation or patient-public-involvement (PPI) processes [36,37] to refine language or presentation for non-scientific audiences. Nevertheless, the guidelines are meant to be applicable to exercise performed in rehabilitation settings, fitness centers, and people's homes.

Population to whom the guidelines are meant to apply. The guidelines are meant to apply to adults with SCI who are not active above and beyond daily activities. Given the characteristics of study participants included in the evidence of the systematic review, the guidelines apply to men and women aged 18-64 years with chronic SCI ( > 12 months post-onset), neurological level C3 or lower, injured from traumatic or non-traumatic causes. The guidelines may also be appropriate for individuals with a SCI $<12$ months postonset, aged 65 years or older, and people with comorbid conditions; however, given the lack of research involving these groups, such individuals should consult a health care provider prior to beginning an exercise program.

Target users of the guidelines. The intended guideline audience consists of scientists; people living with SCI, their families, attendant care and health care providers (e.g., physicians, physiotherapists, occupational therapists and recreation therapists); qualified exercise professionals (e.g., certified personal trainers); exercise physiologists/kinesiologists working in academic, health care or community settings; and organizations that provide information and services to people with SCI. The guideline may be used to design exercise studies and programs, to inform standards of care, and to inform policies to promote fitness and health.

\section{The guidelines and the preamble}

The panel agreed unanimously that (a) there was sufficient quality evidence to formulate exercise guidelines for adults 
Table 3 Survey feedback from participants who attended the 2016 ISCoS SCI physical activity guideline workshop

\begin{tabular}{|c|c|c|c|c|c|c|}
\hline Question & $N$ & $\begin{array}{l}\% \text { disagree or } \\
\text { strongly disagree }\end{array}$ & $\begin{array}{l}\% \text { neither agree } \\
\text { nor disagree }\end{array}$ & $\begin{array}{l}\% \text { agree or } \\
\text { strongly } \\
\text { agree }\end{array}$ & Mean & SD \\
\hline $\begin{array}{l}\text { Physical activity guidelines for people with SCI should be based on evidence } \\
\text { from studies of people with SCI }\end{array}$ & 30 & 10 & 3.3 & 86.7 & 4.27 & 1.23 \\
\hline $\begin{array}{l}\text { Physical activity guidelines for people with SCI should be developed with } \\
\text { the same rigor as pharmaceutical and other clinical practice guidelines }\end{array}$ & 30 & 16.7 & 6.7 & 76.7 & 4.03 & 1.27 \\
\hline $\begin{array}{l}\text { Physical activity guidelines for people with SCI should be based on the } \\
\text { MINIMUM amount of activity needed to achieve health and fitness benefits }\end{array}$ & 30 & 13.4 & 20.0 & 66.7 & 3.83 & 1.21 \\
\hline I intend to use the SCI physical activity guidelines in my clinical practice. & 22 & 9.1 & 9.1 & 81.8 & 4.18 & 1.22 \\
\hline $\begin{array}{l}\text { In my country, it is feasible to put SCI physical activity guidelines into } \\
\text { practice }\end{array}$ & 26 & 0.0 & 23.1 & 76.9 & 3.96 & .66 \\
\hline $\begin{array}{l}\text { It is important that SCI physical activity guidelines are consistent across } \\
\text { countries }\end{array}$ & 26 & 3.8 & 7.7 & 88.4 & 4.38 & .80 \\
\hline
\end{tabular}

Responses were made on 5 -point scales $(1=$ strongly disagree; $5=$ strongly agree). $N$ fluctuates because some participants declined to respond to some questions

with chronic SCI, but not acute SCI, and (b) evidence was sufficient to formulate guidelines to improve fitness and cardiometabolic health, but not bone health, of adults with chronic SCI. The panel decided to develop separate guidelines for improving fitness and for improving cardiometabolic health outcomes. The panel's reasoning reflected the evidence overview in Table 2. Specifically, evidence for the combined upper-body aerobic plus strength-exercise prescription supports improvements in all three fitness outcomes across AIS A-D, but it does not support improvements in the cardiometabolic health outcomes. In contrast, evidence for the upper-body aerobic-exercise only prescription does support the cardiometabolic health outcomes, but only for AIS A-C (to improve body composition) and AIS A-B (to reduce cardiovascular risk). Furthermore, the aerobic-only prescription has support for improving just two out of the three fitness outcomes-cardiorespiratory fitness and muscle strength - and for cardiorespiratory fitness, the evidence is limited to AIS A-B. Given the limitations of the evidence for each prescription, the panel reasoned that combining evidence for the fitness and cardiometabolic outcomes into a single guideline would bring down the overall strength of the guideline with regard to improving the fitness outcomes. Furthermore, the panel felt it was important to create scientific guidelines that were clearly linked to the empirical evidence; to do so separate guidelines for fitness and cardiometabolic health outcomes were required.

When formulating the guidelines, the panel decided to collapse the outcomes of cardiorespiratory fitness and power output under the label of 'cardiorespiratory fitness' because of the strong association between important measures representing both outcomes, such as peak oxygen uptake and peak power output during a maximal graded exercise test [38]. The panel agreed with the systematic review [28] authors' use of the term 'cardiometabolic health', which reflected measures of body composition and cardiovascular risk factors.

The guidelines are presented in Fig. 2. To improve cardiorespiratory fitness and muscle strength, the guideline is: 20 min of moderate to vigorous intensity aerobic exercise 2 times per week AND 3 sets of strength exercises for each major functioning muscle group, at a moderate to vigorous intensity, 2 times per week. This guideline reflects the minimum frequency, intensity, and duration of exercise involving combined upper-body aerobic plus strength exercise yielding significant improvements in fitness outcomes. To improve cardiometabolic health, the guideline is 30 min of moderate to vigorous intensity aerobic exercise 3 times per week. This guideline reflects the minimum frequency, intensity, and duration of upper-body aerobic exercise that has been shown to significantly improve the cardiometabolic health outcomes.

The panel then graded the strength of both guidelines $[34,35]$. The panel voted 11-1 in favor of endorsing the fitness guideline with a "strong recommendation". Of note, apart from some minor differences to enhance clarity, the exercise guideline to improve fitness is the same as the 2011 SCI PA guidelines [19]

The exercise guideline to improve cardiometabolic health is a new guideline. There was unanimous agreement that this is not a "strong recommendation." The panel voted 111 in favor of endorsing it as a "conditional recommendation" given concerns about limited generalizability, and uncertainty as to whether exercise performed at the recommended level can lead to 'optimal' cardiometabolic health or merely induce statistically significant improvements in the types of measures being used as indicators of cardiometabolic health in the research literature (e.g., lipid profiles, inflammatory markers, fat mass) [39]. 
Table 4 Stakeholder evaluations of the guidelines

\begin{tabular}{|c|c|c|c|c|c|c|c|c|}
\hline \multirow[t]{3}{*}{ Questions } & \multicolumn{4}{|c|}{ SCI consumers } & \multicolumn{4}{|c|}{ SCI clinicians } \\
\hline & \multicolumn{2}{|c|}{$\begin{array}{l}\text { Fitness } \\
\text { guideline }\end{array}$} & \multicolumn{2}{|c|}{$\begin{array}{l}\text { CM health } \\
\text { guideline }\end{array}$} & \multicolumn{2}{|c|}{$\begin{array}{l}\text { Fitness } \\
\text { guideline }\end{array}$} & \multicolumn{2}{|c|}{$\begin{array}{l}\text { CM health } \\
\text { guideline }\end{array}$} \\
\hline & $N$ & M (SD) & $n$ & M (SD) & $N$ & $\mathrm{M}(\mathrm{SD})$ & $n$ & M (SD) \\
\hline Is the guideline appropriate for all individuals with SCI? & 44 & $4.59(2.03)$ & 44 & $4.41(1.70)$ & 13 & $4.54(1.94)$ & 13 & $4.77(1.69)$ \\
\hline $\begin{array}{l}\text { Is the guideline realistic if the person is motivated and has all resources } \\
\text { necessary? }\end{array}$ & 45 & $5.87(1.38)$ & 45 & $5.51(1.41)$ & 13 & $6.31(0.95)$ & 13 & $5.92(1.12)$ \\
\hline $\begin{array}{l}\text { Does the guideline reflect the amount, type, and intensity of PA that people } \\
\text { with SCI are likely to do? }\end{array}$ & 45 & $4.53(1.71)$ & 45 & $4.11(1.92)$ & 12 & $4.25(1.49)$ & 13 & $4.46(1.39)$ \\
\hline How confident are you that you can meet this guideline? & 45 & $5.29(2.00)$ & 44 & $4.55(1.90)$ & & & & \\
\hline How confident are you that people with paraplegia can meet this guideline? & 43 & $5.16(1.85)$ & 44 & $4.98(1.85)$ & 13 & $5.92(.86)$ & 13 & $5.00(1.41)$ \\
\hline How confident are you that people with tetraplegia can meet this guideline? & 38 & $4.03(1.75)$ & 36 & $3.83(1.65)$ & 13 & $4.38(1.66)$ & 13 & $3.69(1.55)$ \\
\hline Does the guideline provide useful information for people with SCI? & 45 & $5.53(1.47)$ & 45 & $5.18(1.57)$ & 13 & $5.54(1.71)$ & 13 & $5.62(1.33)$ \\
\hline $\begin{array}{l}\text { Does the guideline provide useful information for health care providers and } \\
\text { fitness professionals? }\end{array}$ & 45 & $5.38(1.70)$ & 42 & $5.07(1.60)$ & 13 & $5.92(1.61)$ & 13 & $5.85(1.41)$ \\
\hline $\begin{array}{l}\text { Does the guideline provide clear instructions about how much PA should be } \\
\text { done in a week? }\end{array}$ & 45 & $5.49(1.95)$ & 45 & $5.60(1.54)$ & 13 & $5.62(1.81)$ & 13 & $5.62(1.61)$ \\
\hline Does the guideline provide clear instructions about the intensity level of PA? & 45 & $5.13(1.85)$ & 45 & $5.22(1.74)$ & 13 & $4.77(2.09)$ & 13 & $4.77(1.64)$ \\
\hline $\begin{array}{l}\text { Does the guideline provide clear instructions about how much PA should be } \\
\text { done in one session? }\end{array}$ & 45 & $4.44(2.05)$ & 45 & $5.29(1.70)$ & 13 & $4.92(1.75)$ & 13 & $5.62(1.26)$ \\
\hline $\begin{array}{l}\text { If you are a health care provider or fitness professional, would you use this in } \\
\text { your practice? }\end{array}$ & & & & & 13 & $6.08(1.55)$ & 11 & $6.00(1.41)$ \\
\hline
\end{tabular}

Note. All Items were rated on a 7-point scale with higher scores indicating more positive ratings. $N$ fluctuates because some participants declined to respond to some questions

$C M$ cardiometabolic, $P A$ physical activity

Following the International meeting and peer review, KAMG and JWvdS made minor textual edits to the preamble and guidelines, leading to the final versions (Figs. 1 and 2). The fitness guideline stipulates adults with a SCI "should engage" in the recommended exercise prescription, whereas the cardiometabolic health guideline stipulates that adults with a SCI "are suggested to engage" in the recommended exercise prescription. Language for the cardiometabolic health guideline was changed from "should engage" to "are suggested to engage" after the panel meeting. These differences in language reflect differences in the strength of the recommendations [35]. All 29 panelists read a draft of this paper, including the final version of the preamble and guidelines; 28 approved the guidelines through an email voting procedure. One panelist declined to endorse the guidelines.

\section{Updating procedure}

Panelists agreed that the guidelines should be reviewed and updated at least every five years. The update could be aligned with the 2-3 years timeline for updating SCIRE. The panel recommended updates include an assessment of the quality and quantity of evidence and follow a protocol that aligns with AGREE-II.

\section{Stakeholder feedback}

Thirty ISCOS workshop participants (87\% women) from 14 countries completed the survey. Participants were rehabilitation specialists $(57 \%)$, medical doctors $(20 \%)$, scientists (10\%), SCI consumers (3\%) and others (10\%). High levels of agreement with survey items (see Table 3) were interpreted as strong endorsement of the guideline development process.

Mean item responses from SCI consumers and clinicians on the guideline survey (Table 4) were above the scale midpoint (i.e., $>4$ ) except for the item assessing confidence that people with tetraplegia can meet the cardiometabolic health guideline. Scores for the fitness guideline tended to be higher than for the health guideline on items pertaining to appropriateness, confidence in achieving, and utility of the guidelines. The health guideline tended to have higher scores on items pertaining to clarity of instructions. These data will help to inform translation of these scientific guidelines into guidelines for use in clinical and community settings [36].

\section{AGREE II evaluation}

The guidelines received an overall quality score of 7 out of 7 and were recommended for use. Ratings for each domain, 
Fig. 2 Scientific exercise guidelines for adults with spinal cord injury. Details on how "moderate to vigorous intensity" was defined/quantified in the studies used to formulate the guideline can be found in tables e-10 and e-11 available at: http://www.neurology.org/ content/early/2017/07/21/WNL. 0000000000004224/suppl/DC1

\section{FITNESS GUIDELINE}

For cardiorespiratory fitness and muscle strength benefits, adults with a spinal cord injury should engage in at least:

20 minutes of moderate to vigorous intensity aerobic exercise 2 times per week

AND

3 sets of strength exercises for each major functioning muscle group, at a moderate to vigorous intensity, 2 times per week

\section{CARDIOMETABOLIC HEALTH GUIDELINE}

For cardiometabolic health benefits, adults with a spinal cord injury are suggested to engage in at least:

30 minutes of moderate to vigorous intensity aerobic exercise 3 times per week areas for improvement, and subsequent minor modifications to this document, are presented in Supplement 3.

\section{Discussion}

Through this international project, scientific exercise guidelines were developed for adults with SCI using a new evidence base [28] and AGREE II reporting criteria [20]. The guidelines were developed in partnership with key stakeholders using a rigorous, systematic, participatory process, that followed the gold-standard approach for formulating clinical practice guidelines $[7,8,20]$. Two guidelines were formulated: (1) a guideline stipulating that to improve cardiorespiratory fitness and muscle strength, adults with SCI should engage in at least $20 \mathrm{~min}$ of moderate to vigorous intensity aerobic exercise 2 times per week, and three sets of strength exercises for each major functioning muscle group, at a moderate-vigorous intensity, 2 times per week. This guideline affirms the 2011 SCI PA guidelines [19] and has been updated to align with the evidence base by referring to 'exercise' rather than 'PA'; and (2) a new guideline, which states that for cardiometabolic health benefits, adults with SCI are suggested to engage in at least $30 \mathrm{~min}$ of moderate to vigorous intensity aerobic exercise 3 times per week. The panel considered the fitness guideline to be a strong recommendation and the cardiometabolic health guideline to be a conditional recommendation [35]

Importantly, both guidelines advise a lower frequency and duration of aerobic exercise than the amount recommended for the general population (150 $\mathrm{min} /$ week) [2-5]. This difference reflects the use of the minimal effective dose of exercise provided by SCI-specific evidence, instead of the optimal dosage of PA derived from the able-bodied evidence underpinning PA guidelines for the general population (e.g., [6]). The lower frequency and duration also reflects that people with SCI are less active and more physically deconditioned than most able-bodied adults [15, 16]. As such, people with SCI can experience improvements in fitness and indices of cardiometabolic health from relatively small doses of exercise, similar to what has been found in apparently healthy but inactive individuals, people living with chronic disease, and people living with other disabilities [17]. This body of evidence from non-SCI populations also indicates that the same exercise prescription can lead to different responses in people with differing baseline PA, fitness, or health levels [17]. Given insufficient SCI-specific evidence [17], it is not clear how such baseline differences influence fitness and cardiometabolic responses to the SCI guidelines. Furthermore, regardless of baseline fitness and activity levels, physiological, autonomic and hormonal responses to exercise can differ between people with and without SCI, particularly in those with higher-level 
lesions [40]. These points attest to the importance of using SCI-specific evidence to develop SCI-specific exercise guidelines [18].

\section{Applicability}

The panel identified numerous intrapersonal, interpersonal, community, institutional and policy-level barriers and some facilitators to applying the guidelines. Most of these factors have been previously identified and reviewed in the SCI research literature (e.g., lack of accessible exercise equipment and venues, costs of memberships and equipment, lack of transportation) [13, 14]. However, the panel also identified barriers and facilitators unique to these guidelines. One potential barrier is that specifying different guidelines for improving fitness and cardiometabolic health might create confusion (i.e., people may not be sure which guideline to follow), as might having guidelines that differ from what is promoted for the general population. A second possible barrier is that the term 'exercise' (as opposed to 'physical activity') in the guideline may constrain thinking about types of activities that people with SCI can participate in. A third concern was that the importance of improving one's fitness might be overshadowed by launching a new cardiometabolic health guideline. The panel deliberated these concerns extensively and concluded that efforts to resolve these issues (e.g., attempting to combine the two guidelines) would require deviation from the scientific evidence. In order to maintain the scientific integrity of the guideline development process, the panel emphasized the distinction between scientific exercise guidelines versus clinical and community practice guidelines. The present guidelines are rigorously linked to an underlying evidence base and have not been reworded or simplified for endusers. The panel acknowledged that a comprehensive, community-engaged strategy is needed for translating the scientific guidelines into clinical and community practice guidelines [36] that can be easily understood by SCI consumers and the people who support them.

Several facilitators were also raised. First, because the SCI exercise guidelines are derived from SCI-specific evidence, the SCI population may be more accepting of these guidelines than of the WHO guidelines which were not developed with consideration of people with SCI. Second, with two guidelines to work with, fitness professionals and clinicians can now better tailor exercise programs to individual needs, values, and preferences. Third, an evidencebased exercise guideline to promote cardiometabolic health could increase awareness of the need for exercise programs and services for people with SCI, which could help with obtaining funding for such services through health care systems and insurance. And finally, panel members emphasized the value of engaging key stakeholders in the guideline development process as these individuals and groups could 'champion' guideline promotion and implementation.

The panel identified several practical implications associated with releasing the exercise guidelines. First, with two different guidelines for fitness and cardiometabolic health, adults with SCI and their health care providers may need education on why and how the guidelines differ. Second, addition of a 3 times/week guideline for cardiometabolic health may demand additional time and resources of SCI exercise programs currently operating to meet the existing SCI guidelines [19] for twice-weekly exercise. Supports may be needed to help people complete some or all exercise sessions at home (e.g., information on how to exercise at home, where to acquire home-based exercise equipment). This implication may be particularly applicable to adults with tetraplegia. Stakeholder evaluations indicated lower confidence in this group's ability to meet the guidelines versus adults with paraplegia (Table 4). Likewise, supports are needed to sustain adherence to the guidelines; for instance, through ongoing physical activity counseling whereby informational and behavioral strategies are provided to support SCI consumers in their long-term efforts to be active [41]. Third, there may be financial costs involved for people with SCI adhering to the guidelines (e.g., transportation to exercise facilities). Cost-savings analyses can support insurance providers in making decisions about coverage for such costs (e.g., an analysis of the reduction of medical costs for treating cardiometabolic disease when an adult with SCI adheres to the guidelines). Fourth, educational resources may need to be developed to remove existing informational barriers for fitness and health providers, making exercise programs and facilities more inclusive for adults with SCI [13]. Finally, funding is required for guideline dissemination, as well as monitoring and auditing impact and uptake. The panel identified some potential funders for these activities and for multicenter trials assessing the impact of adherence to the guidelines on fitness, health and other life domains.

\section{Dissemination and implementation}

The scientific exercise guidelines will be disseminated to the scientific community through publications in peerreviewed scientific journals and presentations at local, national and international conferences and meetings. The guidelines must undergo a rigorous and systematic consumer engagement/patient-public involvement (PPI) [36,37] before widespread dissemination. This process will involve engaging with SCI consumers and other key stakeholder groups (see "Target users of the guidelines") to determine how to optimally present/message the scientific guidelines to these groups, and the types of informational resources 
needed to facilitate guideline uptake and implementation (e.g., resources that explain the concept of exercise intensity, or provide sample workout plans for implementing both exercise guidelines into a single workout plan). Our preliminary survey of SCI consumers and SCI clinicians can help inform this process (Table 4), which is already underway in Canada and the UK. Subsequent papers will be published detailing these activities in order to provide a template for groups in other countries to undertake their own consumer-engagement/PPI processes to make the guidelines relevant to local contexts [36]

Panel members emphasized that processes to make the guidelines relevant to particular environments or settings must not alter the scientific integrity of the guidelines. Specifically, changes cannot be made to the exercise dose or to the population targeted by the guidelines. Any additions to the guidelines must be based on SCI research evidence and must be reported according to AGREE II reporting criteria $[8,20]$. Supplementary information can be provided on the types of exercise equipment (e.g., hand bikes, free weights) available in a particular setting that can be used to achieve the guidelines, but the recommended type of exercise (e.g., upper-body aerobic exercise) cannot be changed. The panel also recommended forward- and backtranslations of the guidelines into other languages, and engagement of local experts in SCI and exercise to ensure translations adequately capture the guidelines.

The panels generated long lists of national (e.g., Multidisciplinary Association for SCI Professionals [MASCIP], National Center on Health, Physical Activity, and Disability [NCHPAD], Spinal Cord Injury Canada) and international (e.g., Exercise is Medicine ${ }^{\mathrm{TM}}$ Global Health Initiative, ISCoS) partner organizations through which the guidelines can be disseminated after undergoing a consumer engagement/PPI process $[36,37]$. Through these channels, the guidelines will reach consumers and health care practitioners. Examples of dissemination strategies include webinars, brief summaries of this manuscript and the supporting systematic review for organizational newsletters and bulletins, and brief online videos to explain the guidelines and provide ideas for implementation in various settings.

\section{Monitoring/auditing criteria [surveillance]}

To measure guideline dissemination, the panel recommended using the number of downloads and citations of this paper, and the number of downloads and hits on social media when the guidelines are disseminated through the channels described above. The panel considered monitoring exercise and other forms of PA among adults with SCI to be important for providing benchmarks and assessing the impact of the guidelines. An operational definition for benchmarks could be the percentage of an SCI population in an area meeting the guidelines [42], which is expected to be relatively stable in the absence of PA interventions [43]. Although population-based baseline estimates of PA in adults with SCI have been undertaken in some regions [4446], and are underway in some European countries [47], to the panel's knowledge, PA is not being monitored in people with SCI on a national or international level. Possibilities for nationwide PA surveys need to be explored in other countries, or at least possibilities for tracking PA in cohorts of adults with SCI (e.g., patients who are part of registries, Paralympic athletes).

\section{Future research}

Through their examination and discussions of the scientific evidence, members of all three expert panels identified numerous gaps in the literature that currently limit knowledge and guideline development regarding the use of exercise and other forms of PA to improve health and wellbeing in people with SCI. Some of these gaps have been previously identified and described in the systematic review [28]. Importantly, the need for high-quality, controlled studies regarding the effects of FES and ambulation exercise received considerable deliberation among the expert panels. These clinically popular exercise types could not be included in the guidelines, because there were less than two high-quality studies regarding the effects of FES or ambulation on an outcome [28] (i.e., insufficient evidence to underpin a clinical practice guideline [33]). Additional research questions and gaps identified by the panels can be found in Supplement 4, and for example allude to the need for research on long-term adherence to the guidelines, if/ what progression in the exercise prescriptions are needed to continue to derive benefits, and on SCI-specific mechanisms related to exercise and cardiometabolic health. The panel recommended writing a paper on the most important research questions regarding PA for people with SCI. Before doing this, additional key stages required are checking of existing research priorities, interim prioritization and a meeting with stakeholders to reach final consensus on the top research priorities [48].

\section{Summary}

This paper has described the process used to develop evidence-based, scientific guidelines that specify the type and minimum dose of exercise necessary to improve fitness and cardiometabolic health in adults with SCI. The guidelines were developed using transparent and rigorous steps that align with international best-practices for developing clinical practice guidelines. Through this process, a new scientific guideline was formulated regarding the type and minimum dose of exercise for the achievement of 
cardiometabolic health benefits. In addition, using new evidence, the 2011 SCI PA guidelines were updated and endorsed as the minimum dose of exercise required to achieve fitness benefits. Consumer engagement/patientpublic involvement (PPI) [36,37], processes must now be undertaken to translate the scientific guidelines into community and clinical practice guidelines. These scientific guidelines represent an important step toward the international harmonization of exercise guidelines for adults with SCI, and a foundation for developing exercise policies and programs for people living with SCI around the world.

Acknowledgements We gratefully acknowledge the contributions during the panel meetings of Dr Kristen Clements (NCSEM, Loughborough University, UK), Adrienne Sinden (MSc; Canadian Disability Participation Project) and Kendra Todd (BSc; University of British Columbia, Canada).

Funding The guideline development project was funded by a grant from the Rick Hansen Institute. The European consensus panel meeting was funded by grants from Loughborough University and the UK Higher Education Institute. The Canadian panel meeting was supported through contributions of meeting space by the Ontario Neurotrauma Foundation.

\section{Compliance with ethical standards}

Conflict of interest The authors declare that they have no competing interests.

Open Access This article is licensed under a Creative Commons Attribution-NonCommercial-NoDerivatives 4.0 International License, which permits any non-commercial use, sharing, distribution and reproduction in any medium or format, as long as you give appropriate credit to the original author(s) and the source, and provide a link to the Creative Commons license. You do not have permission under this license to share adapted material derived from this article or parts of it. The images or other third party material in this article are included in the article's Creative Commons license, unless indicated otherwise in a credit line to the material. If material is not included in the article's Creative Commons license and your intended use is not permitted by statutory regulation or exceeds the permitted use, you will need to obtain permission directly from the copyright holder. To view a copy of this license, visit http://creativecommons.org/licenses/by-nc-nd/4.0/.

\section{References}

1. Tremblay MS, Shephard RJ, Brawley LR. Research that informs Canada's physical activity guides: an introduction. Can J Public Health. 2007;98(Suppl 2):S1-8.

2. ODPHP. Physical Activity Guidelines Advisory Committee Report, 2008 [last accessed 22 Aug 2017]. https://health.gov/pa guidelines/report/.

3. WHO. Global recommendations on physical activity for health, 2010 [last accessed 22 Aug 2017]. http://www.who.int/ dietphysicalactivity/factsheet_recommendations/en/.

4. UK CMO. Start active, stay active: report on physical activity in the UK, 2011 [last accessed 22 Aug 2017]. http://www.gov.uk/ government/publications/start-active-stay-active-a-report-onphysical-activity-from-the-four-home-countries-chief-medicalofficers.
5. Tremblay MS, Warburton DE, Janssen I, Paterson DH, Latimer AE, Rhodes RE, et al. New Canadian physical activity guidelines. Appl Physiol Nutr Metab. 2011;36:36-46.

6. Warburton DE, Charlesworth S, Ivey A, Nettlefold L, Bredin SS. A systematic review of the evidence for Canada's physical activity guidelines for adults. Int J Behav Nutr Phys Act. 2010;7:39.

7. WHO. Handbook for guideline development, 2014 [last accessed 22 Aug 2017]. http://apps.who.int/medicinedocs/en/m/abstract/ Js22083en/.

8. Brouwers MC, Kho ME, Browman GP, Burgers JS, Cluzeau F, Feder G, et al. AGREE II: advancing guideline development, reporting and evaluation in health care. CMAJ. 2010;182, E839-E842.

9. Requejo PS, Mulroy SJ, Haubert LL, Newsam CJ, Gronley JK, Perry J, et al. Evidence-based strategies to preserve shoulder function in manual wheelchair users with spinal cord injury. Top Spinal Cord Inj Rehabil. 2008;13:86-119.

10. Byrne DW, Salzberg CA. Major risk factors for pressure ulcers in the spinal cord disabled: a literature review. Spinal Cord. 1996;34:255-63.

11. Krassioukov A, Biering-Sorensen F, Donovan W, Kennelly M, Kirshblum S, Krogh K, et al. International standards to document remaining autonomic function after spinal cord injury. J Spinal Cord Med. 2012;35:201-10.

12. Griggs KE, Price MJ, Goosey-Tolfrey VL. Cooling athletes with a spinal cord injury. Sports Med. 2015;45:9-21.

13. Martin Ginis KA, Ma JK, Latimer-Cheung AE, Rimmer JH. A systematic review of review articles addressing factors related to physical activity participation among children and adults with physical disabilities. Health Psychol Rev. 2016;10:478-94.

14. Fekete, C. Rauch, A. Correlates and determinants of physical activity in persons with spinal cord injury: a review using the international classification of functioning, disability and health as reference framework. Disabil Health J. 2012;5:140-50.

15. Haisma JA, van der Woude LH, Stam HJ, Bergen MP, Sluis TA, Bussmann JB. Physical capacity in wheelchair-dependent persons with a spinal cord injury: a critical review of the literature. Spinal Cord. 2006;44:642-52.

16. van den Berg-Emons RJ, Bussmann JB, Stam HJ. Accelerometrybased activity spectrum in persons with chronic physical conditions. Arch Phys Med Rehabil. 2010;91:1856-61.

17. Warburton DE, Bredin SS. Reflections on physical activity and health: what should we recommend? Can J Cardiol. 2016;32:495-504.

18. Martin Ginis KA. Letter to the editor. J Sci Med Sport. 2016;19:604.

19. Martin Ginis KA, Hicks AL, Latimer AE, Warburton DE, Bourne C, Ditor DS, et al. The development of evidence-informed physical activity guidelines for adults with spinal cord injury. Spinal Cord. 2011;49:1088-96.

20. Brouwers MC, Kerkvliet K, Spithoff K. The AGREE reporting checklist: a tool to improve reporting of clinical practice guidelines. BMJ. 2016;352:i1152.

21. Pelletier CA, Totosy de Zepetnek JO, MacDonald MJ, Hicks AL. A 16-week randomized controlled trial evaluating the physical activity guidelines for adults with spinal cord injury. Spinal Cord. 2015;53:363-67.

22. Hicks AL, et al. The effects of exercise training on physical capacity, strength, body composition and functional performance among adults with spinal cord injury: a systematic review. Spinal Cord. 2011;49:1103-27.

23. Goosey-Tolfrey VL, Sutton L. Body composition in chronic disease and disability. In: Stewart AD, Sutton L, (eds). Body composition in sport, exercise and health. New York, NY: Routledge; 2012. p. 166-86. 
24. SCIRE. SCIRE rehabiliation evidence: cardiovascular health and exercise 2014 [cited 16 Jan 2017]. https://scireproject.com/evidence/ rehabilitation-evidence/cardiovascular-health-and-exercise/.

25. Zhang Y, Guan Z, Reader B, Shawler T, Mandrekar-Colucci S, Huang K, et al. Autonomic dysreflexia causes chronic immune suppression after spinal cord injury. J Neurosci. 2013;33:12970-981.

26. Neefkes-Zonneveld CR, Bakkum AJ, Bishop NC, van Tulder MW, Janssen TW. Effect of long-term physical activity and acute exercise on markers of systemic inflammation in persons with chronic spinal cord injury: a systematic review. Arch Phys Med Rehabil. 2015;96:30-42.

27. Garshick, E., Kelley, A., Cohen, SA., Garrison, A., Tun, CG., Gagnon, D. et al. A prospective assessment of mortality in chronic spinal cord injury. Spinal Cord. 2005;43:408-16.

28. van der Scheer JW, Martin Ginis KA, Goosey-Tolfrey VL, Hicks AL, Ditor DS, West CA et al. Effects of exercise on fitness and health of adults with spinal cord injury: a systematic review. Neurology (e-pub ahead of print 21 July 2017; doi:10.1212/WNL. 0000000000004224).

29. ACSM. ACSM's guidelines for exercise testing and prescription. Philadelphia, PA: Lippincott Williams \& Wilkins; 2013.

30. Caspersen CJ, Powell KE, Christenson GM. Physical activity, exercise, and physical fitness: definitions and distinctions for health-related research. Public Health Rep. 1985;100:126-31.

31. Eng JJ, Teasell R, Miller WC, Wolfe DL, Townson AF, Aubut JA, et al. Spinal cord injury rehabilitation evidence: methods of the SCIRE systematic review. Top Spinal Cord Inj Rehabil. 2007;13:1-10.

32. Balshem H, Helfand M, Schunemann HJ, Oxman AD, Kunz R, Brozek J, et al. GRADE guidelines: 3. Rating the quality of evidence. J Clin Epidemiol. 2011;64:401-06.

33. Petitti DB, Teutsch SM, Barton MB, Sawaya GF, Ockene JK, DeWitt T. Update on the methods of the U.S. preventive services task force: insufficient evidence. Ann Intern Med. 2009;150:199-205.

34. Andrews JC, Schunemann HJ, Oxman AD, Pottie K, Meerpohl JJ, Coello PA, et al. GRADE guidelines: 15 . Going from evidence to recommendation-determinants of a recommendation's direction and strength. J Clin Epidemiol. 2013;66:726-35.

35. Andrews, J., Guyatt, G., Oxman, AD., Alderson, P., Dahm, P. \& Falck-Ytter, Y. et al. GRADE guidelines: 14. Going from evidence to recommendations: the significance and presentation of recommendations. J Clin Epidemiol. 2013;66:719-25.

36. Harrison MB, Legare F, Graham ID, Fervers B. Adapting clinical practice guidelines to local context and assessing barriers to their use. CMAJ. 2010;182:E78-E84.
37. Straus SE, Tetroe J, Graham ID. Knowledge translation in health care: moving from evidence to practice. Chichester, UK: Blackwell Publishing Ltd; 2009.

38. de Groot S, Adriaansen JJ, Tepper M, Snoek GJ, van der Woude LH, Post MW. Metabolic syndrome in people with a longstanding spinal cord injury: associations with physical activity and capacity. Appl Physiol Nutr Metab. 2016;41:1190-96.

39. Groah SL, Nash MS, Ward EA, Libin A, Mendez AJ, Burns P, et al. Cardiometabolic risk in community-dwelling persons with chronic spinal cord injury. J Cardiopulm Rehabil Prev. 2011;31:73-80.

40. Janssen TW, Hopman MT. Spinal cord injury. In:Skinner JS, (ed). Exercise testing and exercise prescription for special cases: theoretical basis and clinical applications. Baltimore (MD): Lippincott Williams and Wilkins; 2005. p. 203-19.

41. Tomasone JR, Arbour-Nicitopoulos KP, Latimer-Cheung AE, Martin Ginis KA. The relationship between the implementation and effectiveness of a nationwide physical activity telephone counseling service for adults with spinal cord injury. Disabil Rehabil. (e-pub ahead of print 28 December 2016; doi:10.1080/ 09638288.2016.1261415).

42. Rocchi M, Routhier F, Latimer-Cheung AE, Martin Ginis KA, Noreau L, Sweet SN. Are adults with spinal cord injury meeting the spinal cord injury-specific physical activity guidelines? A look at a sample from a Canadian province. Spinal Cord. 2017;55:454-59.

43. Sweet SN, Martin Ginis KA, Latimer-Cheung AE. Examining physical activity trajectories for people with spinal cord injury. Health Psychol. 2012;31:728-32.

44. Martin Ginis KA, Latimer AE, Buchholz AC, Bray SR, Craven $\mathrm{BC}$, Hayes $\mathrm{KC}$, et al. Establishing evidence-based physical activity guidelines: methods for the Study of Health and Activity in People with Spinal Cord Injury (SHAPE SCI). Spinal Cord. 2008;46:216-21.

45. de Groot S, Dallmeijer AJ, Post MW, van Asbeck FW, Nene AV, Angenot EL, et al. Demographics of the Dutch multicenter prospective cohort study 'Restoration of mobility in spinal cord injury rehabilitation'. Spinal Cord. 2006;44:668-75.

46. Post MW, Brinkhof MW, von Elm E, Boldt C, Brach M, Fekete C. et al. Design of the Swiss spinal cord injury cohort study. Am J Phys Med Rehabil. 2011;90(11Suppl 2):S5-16.

47. Gross-Hemmi MH, Post MW, Ehrmann C, Fekete C, Hasnan N, Middleton JW, et al. Study protocol of the international spinal cord injury (InSCI) community survey. Am J Phys Med Rehabil. 2017;96(2Suppl 1):S23-34.

48. van Middendorp JJ, Allison HC, Ahuja S, Bracher D, Dyson C, Fairbank J, et al. Top ten research priorities for spinal cord injury: the methodology and results of a British priority setting partnership. Spinal Cord. 2016;54:341-46.

\section{Affiliations}

Kathleen A. Martin Ginis $\mathbb{D}^{1,2} \cdot$ Jan W. van der Scheer ${ }^{3} \cdot$ Amy E. Latimer-Cheung ${ }^{4} \cdot$ Andy Barrow $^{5} \cdot$ Chris Bourne $^{6}$. Peter Carruthers ${ }^{7} \cdot$ Marco Bernardi $^{8} \cdot$ David S. Ditor $^{9} \cdot$ Sonja Gaudet $^{10} \cdot$ Sonja de Groot $^{11} \cdot$ Keith C. Hayes $^{12}$.

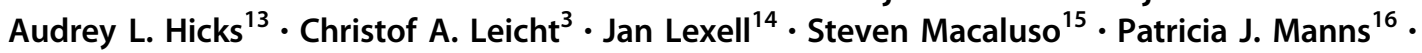
Christopher B. McBride ${ }^{10}$ - Vanessa K. Noonan ${ }^{17}$ - Pierre Pomerleau ${ }^{18} \cdot$ James H. Rimmer $^{19} \cdot$ Robert B. Shaw $^{1}$. Brett Smith ${ }^{20} \cdot$ Karen M. Smith ${ }^{3} \cdot$ John D. Steeves ${ }^{2} \cdot$ Dot Tussler $^{21} \cdot$ Christopher R. West $^{1} \cdot$ Dalton L. Wolfe ${ }^{22}$. Victoria L. Goosey-Tolfrey ${ }^{2}$

\author{
1 University of British Columbia, Kelowna, Canada \\ 2 ICORD, Vancouver, Canada
}

3 Loughborough University, Loughborough, UK

4 Queen's University, Kingston, Canada 
5 Paralympian and Inspirational Speaker, London, UK

6 Spinal Cord Injury Ontario, Ottawa, Canada

7 Bromakin Wheelchairs, Loughborough, UK

8 Sapienza University of Rome, Rome, Italy

9 Brock University, St. Catharines, Canada

10 Spinal Cord Injury British Columbia, Vancouver, Canada

11 University of Groningen, Groningen, The Netherlands

12 Ontario Neurotrauma Foundation, Toronto, Canada

13 McMaster University, Hamilton, Canada

14 Lund University, Lund, Sweden
15 Western University, London, Canada

16 University of Alberta, Edmonton, Canada

17 Rick Hansen Institute, Vancouver, Canada

18 Institut de Réadaptation en Déficience Physique de Québec, Ville de Québec, Canada

19 University of Alabama at Birmingham, Alabama, USA

20 University of Birmingham, Birmingham, UK

21 National Spinal Injuries Centre, Stoke Mandeville Hospital, Aylesbury, UK

22 Parkwood Institute, Lawson Health Research Institute, London, Canada 